\title{
Scholarly Communication in Biblical Studies
}

\author{
Lessons from the Social Sciences \\ Beth M. Sheppard, University of West Georgia
}

\begin{abstract}
During a bibliometric analysis of the scholarship of ninety-five social science faculty members at the University of West Georgia (UWG), observations were made concerning potential differences between how scholarly communication is practiced by the disciplines of the social sciences and biblical studies. The fields appear to diverge on the role of book reviews, prevalence of co-authored materials, use of ORCIDs, and adoption of DOIs. In addition to highlighting these points, the dataset used for the project is described. Finally, a few theological reflections are offered.
\end{abstract}

Dagobert Runes offered the bon mot, "People travel to faraway places to watch, in fascination, the kind of people they ignore at home" (1967, location no. 2373). Although my terminal degree is in biblical studies, I recently had an opportunity to undertake a bibliometric project in what was for me an exotic scholarly land - the University of West Georgia's (UWG) College of Social Sciences (COSS). The task involved analyzing faculty publications in that unit with an eye toward determining whether UWG's Ingram Library could make strategic reductions in collection resources without adversely affecting faculty research trajectories. As with any journey, though, as I was sifting the data, I couldn't help but informally compare and contrast how scholarly communication as practiced by UWG's social sciences faculty appeared to differ from my own experiences of publishing and researching in my home subject of biblical studies. Once I had a fairly substantial list of differences that included 1) the presence or relative lack of the book review as a genre for scholarly communication, 2) inclinations toward collaborative authorship or solo authors, 3) the use of ORCIDs (Original Researcher and Contributor Identifier) and 4) the pervasiveness of DOIs (Digital Object Identifiers) in each field, I also spent some time in trying to make sense of some of the differences theologically. The observations are shared 
below. Before getting to them, however, kicking off with a brief overview of the UWG project and dataset as well as enumerating a few difficulties experienced in creating a comprehensive list of faculty publications is in order.

\section{THE UNIVERSITY OF WEST GEORGIA SOCIAL SCIENCES FACULTY PUBLICATIONS PROJECT}

Let's start with a few words about the University of West Georgia (UWG) at large and then lay out a few details about the College of Social Sciences (COSS). Foremost, unlike the majority of Atla member institutions, UWG is a state university and does not have a religious studies major, though interested students may cobble together a few courses in philosophy and history to declare a religion minor. No classes are taught from a confessional perspective due to the separation of church and state and the fact that the school is supported by taxpayer funding. Within the Regent's system of Georgia, UWG is a comprehensive university. To be more specific, it is a mid-sized regional school with an R3 Carnegie classification. Although known for serving undergraduates, graduate programs have flourished in the last half-dozen years, including a handful of EdD degrees and one PhD in Psychology. Tenure and promotion do require demonstration of scholarly activity-a precept laid out in general terms in the faculty handbook - with each discipline free to provide specific departmental guidelines in how those terms are to be met.

The College of Social Sciences, or COSS as it is known on campus, was selected for the bibliometric analysis since it was poised to undergo transition. At the end of the spring semester 2019, its longterm dean announced her retirement from that position. In the wake of this transition, the campus began investigating whether or not the COSS might be combined with the College of Liberal Arts or perhaps even the College of Sciences and Mathematics. So, with the spotlight on COSS, it was a logical moment for the library to dig into what was happening with regard to scholarly communication in that unit. The project began with instructions from library administration to compile three comprehensive title lists to include:

1) the titles of the journals in which faculty members in COSS publish and those of the monographs and edited works they authored,

2) the journals in which coss faculty members are cited, ${ }^{1}$ 
3) and all of the journals that appear in the bibliographies of their publications.

It is a herculean task and some of that work is still ongoing. This particular study reflects thoughts and findings that arose through the course of completing phase one and also analyzing a small subset of data gathered from phase three.

The project began during the fall semester 2019 and focused on the scholarly output of the ninety-five full-time faculty members in coss who taught in the departments of anthropology, criminology, mass communications, political science, psychology, and sociology.

\section{METHOD}

Determining who served as full-time faculty members in the various COSS departments during the fall semester 2019 was the easiest part of the task. An administrative assistant in the office of the interim COSS dean provided the list. Further, the decision was made to focus on publications irrespective of format that appeared "in print," as opposed to being merely at press, during fiscal years 2014-18. In addition, it didn't matter whether the faculty member was employed all five years at UWG or had been publishing for some portion of those years at another institution. We were simply interested in five years' worth of publications for each individual. After all, we reasoned, a faculty member's research trajectory didn't necessarily shift entirely when he or she moved to UWG. In sum, no publication before June 30, 2013 or after July 1, 2018 made the cut, but those produced while individual faculty members were still employed at other schools did. In addition, co-authorship was considered irrelevant. Regardless of whether the UWG faculty member was the first author (principal investigator), a collaborating contributor, a co-editor, or even a translator, the publication was added into the project. The only requirement was that the UWG faculty member's name had to be included in the byline. Last, each publication was also only counted once. If co-authors, for instance, were both faculty members at UWG, the book, article or chapter was listed under the first UWG author named in the byline. If that first author was prolific and a co-author had no publications to his/her name, the subsequent UWG author was credited with the publication. This allowed us to track a side data point related to the number of faculty members who were actively publishing. 
It ended up that there were several sources that proved useful for determining what materials the coss faculty had published during the period. The primary one turned out to be the annual "Faculty Activity Report" (FAR) that was filed each year by the COSS dean with UWG's office for institutional effectiveness and assessment. FARs include each faculty member's self-reported scholarly activity in a given fiscal year. The CVs faculty posted on their UWG faculty profiles were another useful source for compiling a list of faculty publications. Mining faculty profiles on sites like Google Scholar, Academia.edu, and Research Gate also proved helpful. As it so happens, Google Scholar's own underlying dataset is so large, publication results were unearthed even for UWG faculty members who had not created Google Scholar profiles. Finally, in the quest to create a complete list of faculty publications, each faculty member's name was run through the UWG Ingram Library's OPAC. Since the UWG catalog is shared with other institutions of higher education in Georgia, this ensured that we were able to sweep in a few other book titles that we didn't hold in our own collection and of which we had not been aware.

\section{DIFFICULTIES ENCOUNTERED IN CREATING A MASTER LIST OF FACULTY PUBLICATIONS}

Before reporting the results, a word about the difficulties that were experienced in creating a comprehensive list of faculty publications might prove instructive. It is unlikely that the list that was ultimately complied is completely authoritative. One challenge, for instance, involved disambiguation of faculty names. Some faculty published using various surnames during the five-year span. While a few instances of multiple names for the same faculty member were unearthed through study of their CVs and faculty profiles, it is by no means certain that we always found all publications produced under earlier last names.

Another difficulty involved flaws with the FARs themselves. It is clear that when faculty are filling out their individual forms they are uncertain whether to record items that were merely at press or fully in print; items for UWG's fiscal year which runs July-June, or the calendar year; or how to record books or articles for publications completed in prior years that were recently translated by others, republications of earlier works without any revisions, or subsequent 
editions/revisions of earlier materials. These struggles were evident when the same titles appeared in back-to-back years or the reports or when some titles mentioned in the reports never seem to (or have not yet) made it into print.

The lack of updated CVs on UWG faculty profile pages also made this project difficult. Some faculty CVs were years out of date. A handful of COSS faculty colleagues had not provided CVs for display on the UWG website at all. This is perhaps a function of profile fatigue. Faculty are creating profiles for LinkedIn, the UWG website, the professional associations of their disciplines, Google Scholar, and a variety of other academic repository services besides. Issues of profile exhaustion and expectations that faculty take the lead in selfpromoting their own scholarly output through creating profiles and adding their materials to repositories would likely be good fodder for a separate study in and of itself.

In any case, a final barrier to creating a comprehensive list was related to some faculty members intentionally excluding some materials published on sensitive subjects from public profiles and FARs. These included political party-specific analysis or criticism (perhaps excluded on the grounds that UWG's funding is determined each year by the political party that is in power in Georgia) and pieces on paranormal phenomenon (a subject once quite in vogue amongst UWG researchers in psychology, but regarded as pseudo-science at best in some quarters of the academy). Since UWG faculty profiles, along with the FARs, are subject to Georgia's laws on open records, the reticence to include these sorts of publications is explicable. Searching Google Scholar and the library databases, however, did aid in the discovery of at least some of this material. All told, though, these difficulties, from disambiguating authors' names to placing the responsibility for self-reporting scholarly activity on faculty themselves, to attempts at actively keeping a record of some publications from the public eye, mean that the data set is reasonably accurate, but not necessarily without omissions.

\section{THE RESULTS}

The final list included 346 publications and represented activity by fifty-eight faculty members ( $61 \%$ of the coss full-time faculty). The fact that thirty-seven faculty members did not publish during the five-year span is not alarming and does not reflect badly on them. To 
be sure, a number of them primarily worked in administrative roles elsewhere in the university and taught only rarely during the time period covered by the study. In addition, a few others were designated as clinical faculty and more still held only instructor status. Individuals in these categories are not expected to execute research.

Once the publications list was in hand, each entry was coded by material type: articles, chapters contributed to edited works, book reviews, and books (including sole-authored, co-authored, edited, and co-edited volumes). The results of this scholarly output by the UWG COSS Faculty are available in figure 1.

\section{Figure 1: Scholarly Output}

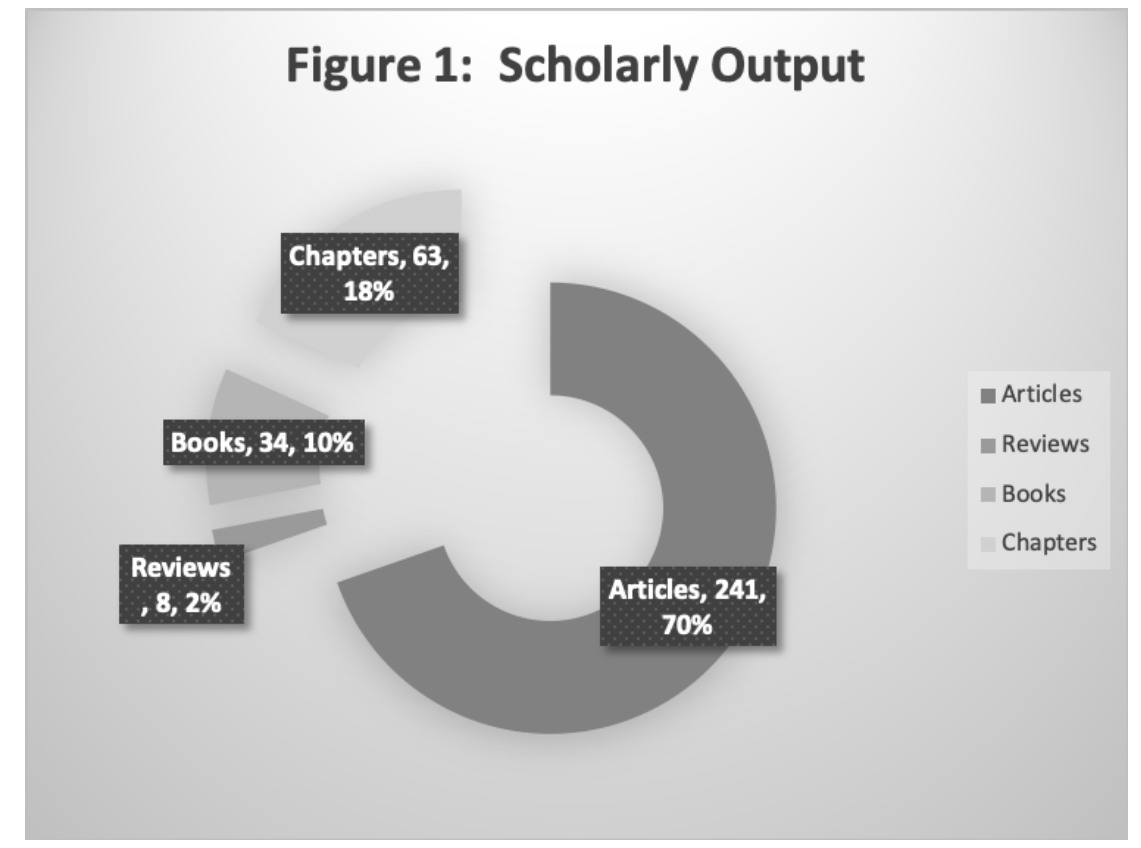

That articles predominated is not necessarily surprising. For virtually any discipline, including biblical studies, the ready availability of good quality journals means that solid article-length research pieces of 3,000-8,000 words can readily find a home. In the case of COSS, articles comprised $70 \%$ of the materials produced, followed by individual chapters at $18 \%$, books at $10 \%$, and reviews a distant last at $2 \%$.

In addition, a random subset of 63 publications, or $18 \%$ of the 346 , was selected for an in-depth analysis of their bibliographies. While $18 \%$ may seem like an odd percentage, this number was due to the fact that our student assistants helped out with the project and were 
asked to find PDFs for as many of the faculty publications as they could during one of their scheduled four-hour long library work slots. Sixty-three was the winning number. This sub-set of sixty-three included sixty-one articles, one monograph, and one book chapter. Each individual entry within the sixty-three reference lists was coded by type. The categories included: 1) book or chapter in a book, 2) journal or newspaper article, 3) government reports, 4) general websites, 5) media/films, 6) TV news, 7) datasets/polls, 8) theses, 9) conference proceedings, 10) survey instruments, 11) laws/acts/bills, 12) unpublished papers, and 13) software. A full breakdown of the number of hits in each category is available in table 1.

\begin{tabular}{|l|c|c|}
\hline \multicolumn{2}{|c|}{ Table 1: Coss References by Type } \\
\cline { 1 - 2 } Books \& chapters in edited books & 1192 & \multirow{2}{*}{$38 \%$} \\
\hline Journals/newspapers & 1630 & $52 \%$ \\
\hline $\begin{array}{l}\text { Government and think tank } \\
\text { reports }\end{array}$ & 123 & \\
\cline { 1 - 2 } $\begin{array}{l}\text { General websites including } \\
\text { university centers }\end{array}$ & 42 & \\
\cline { 1 - 2 } Media/films/TV news & 18 & \\
\cline { 1 - 2 } Datasets/polls & 37 & \\
\cline { 1 - 2 } Theses & 17 & \\
\cline { 1 - 2 } Conference proceedings & 21 & \\
\cline { 1 - 2 } Survey instruments & 12 & \\
\cline { 1 - 2 } Laws/acts/bills & 26 & \\
\cline { 1 - 2 } Unpublished papers & 1 & \\
\cline { 1 - 2 } Software & &
\end{tabular}

There were 3,129 total reference entries in the 63 publications for an average of 49.6 per faculty publication. Of these, 1192 or $38 \%$ were either full books and/or chapters in edited volumes. 52\% were articles from journals or newspapers. The remaining 10\% included all of the other various types of materials upon which faculty relied for their research. Granted, these results blur, to some extent, the differences between so-called "book-focused" disciplines, such as 
biblical studies, that regard the monograph as the pinnacle of scholarly communication, and "article disciplines," like those that make up the COSS at UWG. The obfuscation was due to the fact that, when the reference lists were coded, chapters within edited volumes (which often may be equivalent to articles for purposes of tenure and promotion within the social science disciplines) were not disaggregated from monographs. Of course, one must recall that the main objective of this bibliographic study was to focus on determining what journal title subscriptions might be safely eliminated from the UWG collections and the initial coding scheme for this sample subset of sixty-three titles reflected that primary objective. As additional work with the dataset continues in future months and years, disaggregation of monograph references from chapters in edited volumes might be possible for comparison with another sub-set of the faculty publications.

\section{TWO ROADS DIVERGE-OR DO THEY?}

\section{THOUGHTS ON BIBLICAL STUDIES AND THE COSS STUDY}

Although examining the Coss publications began with the objective of examining journal titles with an eye toward collection development, it turned out that there were four areas involving scholarly communication as practiced by my coss colleagues that were not part of the original itinerary, yet nevertheless snagged my attention because they appear to diverge a bit from how research is shared amongst scholars in the field of biblical studies. These included the role played by book reviews, the practice of collaborative authorship, the appearance of ORCIDs in article bylines, and, finally, the use of DOIs (digital object identifiers) in bibliographies.

\section{Book Reviews}

Let's unpack each of these four elements. First, the fact that there were only eight book reviews represented amongst the three hundred and forty-six UWG social science publications was a fact that may seem astonishing given that reviews are a staple in biblical studies. While not necessarily counting toward tenure and promotion within Bible departments at every institution (and subsequently not necessarily included on the CVs of Bible faculty), reviews are nonetheless a frequent activity in which scholars in biblical studies engage. ${ }^{2}$ Indeed, it is relatively easy to find the reviews that any indi- 
vidual biblical scholar has written (as well as those written about his/ her books) by executing federated searches of library resources using the author's name. There are numerous places where such reviews of monographs and edited works can be published. The Review of Biblical Literature, produced by the Society of Biblical Literature, for instance, features high-quality reviews by doctoral students as well as faculty members of every rank. In addition, many reviews of interest to the field of biblical studies also appear in Reviews in Religion and Theology. Incidentally, our Atla colleague, Suzanne EstelleHolmer at the Yale University Library, has published an entire library guide in which she lists sources that focus on sharing evaluations of books (guides.library.yale.edu/c.php?g=295964\&p=1973160).

The lack of reviews in the social sciences may be the culmination of a decades-long trend in that field. To be specific, while the current issue of the American Sociological Review (ASR) does not list any reviews on its online table of contents, just over a half-century ago Lawrence E. Riley and Elmer A. Spreitzer (1970) expressed the opinion that book reviews in the social sciences were vital to assist scholars to keep current in the field. They observed that, in the 1960s, a good third of $A S R$ featured book reviews (358).

Still, mystified about the low number of reviews in the dataset because thirty-four books had indeed been written by the UWG social sciences faculty in the period, if not necessarily reviewed by others, I questioned the head of UWG's Political Science Department, Chapman Rackaway, who had authored some of the monographs. ${ }^{3}$ I wanted to hear about his view of the role of book reviews in his discipline. He explained that, in the social sciences, "Most of our tenure and promotion guidelines, even at R3 schools such as UWG, incentivize article publishing. Books are much more intensive works but only count as the equivalent of two refereed journal articles so, especially for younger faculty, there is an incentive to go for articles" (pers. comm., July 15, 2020). Presumably, then, if articles are encouraged and books are merely works of supererogation in which tenured full professors might indulge, then it would follow that book reviews would not feature as prominently as they do in Bible. Indeed, just eyeballing the list of the 34 books authored by COSS faculty, it did seem that they were primarily written by senior faculty, though follow-up work of adding faculty rank to the data set would be necessary to confirm the exact number authored by those of each rank. For her part, N. Jane McCandless, who retired as 
Dean of COSS, was gracious to visit with me by phone (July 22, 2017). In that conversation, she revealed that, during her lengthy career, she has regularly completed non-published peer reviews of manuscripts and book proposals for editors at a variety of publishing houses. The idea of publishing a formal review of a published book or even using a review in her research, however, was simply never on her radar. She only consulted them when considering textbooks for adoption in courses.

It appears, then, that the activity of writing and publishing book reviews may be discipline-specific, though subject to change over the course of time as a field develops new modes and preferences for sharing research. At this point in time, though, scholars in biblical studies still share their opinions of other's work through means of book reviews, even if that genre is no longer really in vogue in the social sciences.

\section{Collaborative Authorship}

After dispatching the puzzle concerning the low number of book reviews in the COSS set of publications, focus turned to yet another apparent difference between that data set and practice within the field of biblical studies-preference for undertaking research and writing collaboratively in the social sciences versus alone in Biblical Studies. It turned out that, in our dataset, the preponderance of articles produced in COSS were co-authored. In fact, of the 63 publications, 47 of them (or 75\%) were co-written, leaving only a quarter that were produced by a single researcher. My own guess is that the percentages of co-authored to solo-authored materials would be almost completely reversed in biblical studies, though a formal study of this point is needed. Respondents to a survey undertaken by Taylor \& Francis $(2017,2)^{4}$ concerning collaborative authorship in the humanities and social sciences indicated that the practice of having multiple authors was an emerging trend in both the humanities and social sciences, but that study did not disaggregate larger subjects like religion, let alone a subfield like biblical studies. In an attempt to confirm my hunch that biblical studies remains a single-authordriven discipline, and given that COVID-19 meant I couldn't browse the stacks in the UWG library to access sample publications, I pulled a copy of Jesus, Skepticism \& the Problem of History (Bock and Komoszewski, 2019) off my office shelf to examine it. That was a book to which I had contributed an essay, so it was easily at hand. While that 
volume as a whole benefited by the collaborative work of co-editors, when it came to individual chapters themselves, only three of the seventeen essays were co-authored. Although the published version of the book did not include works cited lists at the end of each chapter nor a final composite bibliography, while I was writing my own contribution (without a collaborator, of course), I had developed a running bibliography. According to that record, I cited sixty-one different resources. It turns out that only seven (or 11.48\%) of the total resources in my works cited list were co-authored. ${ }^{5}$ While this single example does not necessarily prove the point that Bible scholars prefer to go it on their own, the prevalence of single authors over co-authors in the field of biblical studies can also be inferred by looking at the sample bibliographic entries selected for inclusion in the "Student Supplement for the SBL Handbook of Style Second Edition." The authors of that citation resource did not present a single instance of a multi-author work amongst the samples they provided (LeMon and Breed 2015, 2-4, 10, 17). Likewise, in the full SBL Handbook of Style, only single-author examples appear in the section that demonstrates how to cite journals (SBL, 2014, §6.3).

\section{Persistent Author Identifiers (ORCIDs)}

The tendency of authors in the social science disciplines to work closely with collaborators was not the only oddity that reminded me that I was traveling in a strange land when working with the coss dataset. Indeed, I noticed that some publishers had included ORCID (open researcher and contributor ID) numbers in the short author bios that appeared on the PDF versions of the articles themselves. That was an eye opener. One sees institutional affiliations and faculty emails, but generally not ORCIDs in biblical studies author bios. Though, to be sure, a few publishers of Bible content like Sage, which produces the Journal for the Study of the New Testament are ORCID members. ${ }^{6}$ ORCID member publishers have pledged to encourage registration for ORCIDs amongst contributors to their journals. Even so, Sage, as a case in point, does not yet add ORCIDs to the bios in JSNT. This is surprising given that ORCID provides guidance to publishers on the most appropriate ways to display the persistent identifiers on published works (orcid.org/content/journal-article-display-guidelines). In disciplines like the hard sciences, where scholarly communication is primarily article-based, the use of author identifiers often serves as a way to track research produced 
by grant recipients (Dunford and Rosenblum 2018, 236). This may explain the lack of their use in our own field. After all, grant funding for Bible research is very rare indeed.

Regardless of its relationship to tracking grant funding, the use of persistent author identifiers like ORCIDs and other types of persistent author identifiers in the academy at large stretches back almost fifteen years, so one would think the practice would start to catch on soon in biblical studies. Margaret Mering, in her history of their use, pointed out that SCOPUS launched author identifiers in 2006, Clarivate Analytics introduced Researcher IDs in 2008, and ORCID numbers themselves were initiated independent of any particular publisher or discipline in 2012 (Merling 2017, 265-66). That same year, the ISNI (International Standard Name Identifier) was also rolled out, though, granted, the ISNI designation differs a bit from the others because it is also used by composers, musicians, artists, and others whose creative output is not limited to text. Nevertheless, the string used in the ORCID does conform to that of the ISNI (Powell, Hoover, et al. 2019, 627).

For authors who adopted some of the earlier scientific disciplinebased schemes and created author profiles in which they included their publications, both SCOPUS publication lists and any references linked to Researched profiles now merge easily into ORCID profiles. ${ }^{7}$ Given this flexibility, there is no question that the ORCID is emerging as the standard for authenticating authorship and disambiguating author names.

Theological librarians themselves have also recognized the value of ORCIDs. At the seventieth Atla conference, for instance, Carisse Mickey Berryhill, Jason Fikes, and John B. Weaver encouraged attendees to assist young scholars in obtaining ORCIDs $(2016,114)$. The following year, the Atla Taskforce on Scholarly Communication in Religion and Theology urged, "Register for an ORCID iD (it's free) and connect your education and publications as desired. As you work with faculty, scholars, and graduate students, encourage them to register as well" (Anderson, Keck, LeBlanc, and Creamer 2017, 10). While some progress on this front has been made, there is still quite a way to go. That many Bible scholars have not considered obtaining ORCIDs is easily demonstrated by executing a few searches in the ORCID registry (orcid.org/search/node/69). For example, a search for "Society of Biblical Literature" that I executed on June 15, 2020 returned only 221 profiles in which individuals had listed member- 
ship in that organization. Given that there are 5,751 full members, the profiles returned in the search represents only about $3.8 \%$ of that member category (Society of Biblical Literature, 2019). Incidentally, a similar search for "American Theological Library Association" returned only 27 hits. ${ }^{8}$ It might be possible that we librarians simply need to get the word out about ORCIDs. Perhaps one way to promote sign-ups might involve Atla member librarians creating videos about the ORCID registration process that can be distributed to Atla's membership. In turn, individual Atla librarians could share the videos with faculty and graduate students at their respective schools. Another option might take advantage of the fact that, in non-COVID-19 years, many Atla members attend sessions at the Society of Biblical Literature Annual meeting while Atla full-time staff members maintain a vendor booth in the exhibit hall to promote the suite of Atla databases and other products. Might it be possible for Atla member librarians attending SBL to volunteer at the booth with an eye toward encouraging SBL conference attendees who wander by to register with ORCID?

\section{Digital Object Identifiers (DOI)}

The final area in which the social science disciplines seem to diverge from normative practice in biblical studies, given what was observed with the COSS set of publications, is the adoption of DOIs (or, digital object identifiers). DOIs are stable URLs to digital articles, and DOI-based URLs are liberally sprinkled through the bibliographies of the articles and books written by UWG's social science faculty members. In addition, when I looked at the title pages of the UWG faculty members' publications themselves, I noticed that it was not unusual for publishers to include any given article's DOI in the margins, headers, or footers of the final PDF versions made available in the library's subscription databases.

Although based on general observations rather than a solid statistical study, I must confess that I rarely see DOI addresses included in the bibliographies of the biblical studies books and articles that I consult for my own research. Though, to be fair, while DOI was introduced in 1997, it didn't become an ISO standard until 2010, so perhaps scholars are not yet consulting materials that might include DOI to any great extent. Biblical studies publications and articles tend to have long lifespans and are incorporated into research for many years and even decades after their original release dates. 
Another reason why DOIs may not frequently appear in the works cited lists of biblical studies publications may be due to the fact that born-digital publications in biblical studies are a rarity. The Directory of Open Access Journals (DOAJ), for example, generated only twelve entries when I conducted a search using the term "biblical studies." Of those twelve journal titles, three do not yet have any published content and another three do not offer/supply DOIs. That leaves only six journals in that directory that actually do have articles that are marked by DOIs. ${ }^{9}$ This is a concern because a publisher's willingness to pay the fees associated with offering and taking the time to register DOI numbers is often the mark of a worthy and reputable journal as opposed to one that is predatory or, at the least, disreputable. Questionable journals are those that are untried and often unindexed. Predatory ones masquerade as a well-respected publication by employing a similar title and branding scheme. It seems that the goal of predatory journals is to generate revenue streams by scooping up article submission fees paid by unsuspecting potential authors (Tiliuțe 2016, 138). DOIs would cut into the profit margins of these dubious publications, which often eschew offering them. Given that the presence or absence of DOI is a marker of journal quality, this raises the question of what responsibility we, as members of Atla, should take in working with editors and publishers of the many fine Bible and other religious content journals that are not presently incorporating DOIs into the e-versions of their publications to educate them about persistent identifiers and assist them in implementing the DOI scheme.

The issue of publishers' role in promoting DOI aside, the case that individual biblical researchers may not be rapidly incorporating DOI in their bibliographies is, no doubt, complicated by the fact that many documents that scholars access in digital format are either simply scans of print counterparts or PDFs generated from the layout file in the publisher's software. Both of these methods of producing e-versions essentially mean researchers are working with digital surrogates that are virtually indistinguishable from print versions and may not include DOI addresses in headers and footers, unlike what was observed with many of the social science articles in the dataset under examination at UWG. Instead, when it comes to articles related to the Bible, DOI may end up as part of the article's metadata. The upshot, of course, is that the onus is on the researcher to click several times to locate DOI information. Along the way, the 
researcher may be tempted to simply capture the URL in the search engine bar on the page where the PDF itself resides rather than the DOI. This impulse is, of course, contrary to recommended practice according to the SBL Handbook of Style, where DOI is preferred over the simple URL (2014, §6.1.6).

Although not itself a biblical studies journal, Atla's own publication, Theological Librarianship (TL), may be used to illustrate the point about the difficulties researchers in religious studies disciplines may encounter in locating and capturing DOI for use in their works cited lists. To be specific, the earliest issues of $T L$ make an article's DOI visible with other metadata, such as the article title, within the journal management system, but DOI does not actually appear on the linked PDF itself. Further, when a researcher clicks on the PDF, one discovers that it is much more intuitive to cut/paste the general URL that appears in the search engine at that point than to scroll back to capture the DOI from the description of the article. ${ }^{10}$ Even though the DOI for each of the articles, essays, and reviews has recently been made available in a handy index (Hughes 2019, 21-87), nonetheless, this case is illustrative of the struggles to implement new advances and protocols in information access in the fields of theology, Bible, and other religious disciplines in ways that make the researcher's job easier rather than more onerous. We should not, however, be disheartened. We are still in the midst of transitioning to an era in which e-formats are rapidly becoming the norm. In that foreign and new landscape, theological librarians are in the unique position of having the means and the voice through our association to influence best practices for how publishers of Bible research incorporate DOIs into their journals and article PDFs.

\section{THEOLOGICAL REFLECTIONS}

Without a doubt, some of the differences that biblical scholars might discover after visiting the novel lands of the social sciences and observing a handful of points where the disciplines appear to diverge, can be chalked up to simple methodological differences. For instance, there are labs in some fields like research psychology where teams of researchers are the norm, methods such as text coding in sociology that require collaborators to ensure inter-coder reliability, and the reliance on statistical data generated by polling that may require partners to execute. All of these elements would position the social 
science disciplines to be open to collaborative authorship more readily than a humanities-focused field like Biblical studies.

Nevertheless, it behooves theological librarians who operate in, for, and out of theological contexts to speculate about whether some of the differences between the lands of biblical studies and the social sciences might be the result the confessional vantage point adopted by many biblical scholars. In that vein, I want to offer just a few theological reflections.

First, when it comes to the fact that sole rather than co-authorship appears to be the norm in biblical studies, it is important to recognize that sometimes Bible research is undertaken in service of a scholar's devotional activities. In short, biblical scholarship may be, as Anselm put it, a personal act of fides quarens intellectum, or faith seeking understanding. To that end, like private devotions, Bible scholarship naturally is individualistic. Along these same lines, the apparent disciplinary preference in the field of Bible for book reviews (which are generally written by individuals), might be explained as just another mode in which this devotional element in the discipline is expressed. After all, scholars generally choose the titles they would like to evaluate and likely are drawn to one title over another, perhaps for reasons related to personal faith or denominational leaning given that books in Bible are frequently published by presses with particular theological outlooks.

Before leaving the topic of scholarship in service to faith, it also is worthwhile to point out that often biblical scholarship takes the form of exegesis - an activity that is unique to the discipline. It is a method of analyzing the Bible text for the purpose of writing and delivering a sermon. Here we come back again to the individual. While the members of a congregation hopefully benefit from hearing a sermon, very, very rarely do two preachers share a pulpit and preach simultaneously. Sermon preparation and delivery, even when modest input is received by others, tends to be a solo exercise.

By contrast, it seems as though the individual doesn't have such a central role in the social sciences. Rather, the focus of sociology is the group-how groups form, how groups function, and so forth. Even within the field of psychology, which is concerned with the mental well-being of individuals, the aim is preparing individuals to live and function within society (the group). One might speculate, therefore, that social scientists themselves may be pre-disposed to work with others as collaborating authors given the central interests of 
their disciplines, while many who undertake writing and research in biblical studies may be inclined to go it alone.

In addition to the influence of faith in the lives of many Bible scholars, it is important not to lose sight of the role played by moral and justice concerns expressed by faith communities when it comes to issues related to e-resources. Interest in implementing DOIs, or registering for ORCIDs, for instance, might take a back seat in our discipline to worries about accessibility to digital content by those without technology or internet connections. This would not be the only arena in which Atla librarians might express apprehension about inequities related to cost and access in religious publishing (Keck 2018).

As a final theological point to ponder, one might also wish to someday explore what percentage of biblical scholars, if any, view the exercise of promoting one's own publications through the use of scholarly profiles and ORCIDs as verging on prideful boasting. That, of course, would cause us to engage in a rousing discussion related to hamartiology.

Suffice it to say, scholarly communication as undertaken in biblical scholarship in some ways might seem as exotic to a faculty member in the social sciences as were the current trends in that field that I observed in my own brief sojourn with a handful of my social science colleagues' publications. In any event, Runes was correct. Looking at the work done by the social scientists did prompt me to more closely examine and question some aspects of scholarly communication in biblical studies that I had heretofore overlooked. To that end, it is good to be a tourist in another academic discipline on occasion.

\section{WORKS CITED}

Anderson, Clifford Blake, Andrew J. Keck, Jérémie LeBlanc, and Deborah Beth Creamer. 2017. "Scholarly Communication: A Guide for the Perplexed.” Atla Summary of Proceedings 71: 8-12.

Berryhill, Carisse Mickey, Jason Fikes, John B. Weaver. 2016. "Owning their Vices: How Librarians Can Help Graduate Students Develop Publishing Literacy.” Atla Summary of Proceedings 70: 111-16. 
Bock, Darrell and J. Ed Komoszewski, eds. 2019. Jesus, Skepticism \& the Problem of History. Grand Rapids, MI: Zondervan Academic.

Dunford, Robin and Bruce Rosenblum. 2018. "Keeping it Authentic: Reconciling ORCID iDs Gathered at Submission with the Author Manuscript.” Learned Publishing 31: 236-40. doi.org/10.1002/ leap.1159.

Hughes, Barnaby. 2019. "Index of Theological Librarianship, 2008-2019.” Theological Librarianship 12, no. 2: 21-87. doi. org/10.31046/tl.v12i2.554.

Keck, Andrew J. 2018. "Theological Libraries and Scholarly Publishing in Religion and Theology.” Theological Librarianship 11, no. 2: 27-37. doi.org/10.31046/tl.v11i2.518.

LeMon, Joel M. and Brennan W. Breed, eds. 2015. "Student Supplement for The SBL Handbook of Style." Second edition. www.sblsite.org/assets/pdfs/pubs/SBLHSsupp2015-02.pdf.

Mering, Margaret. 2017. "Correctly Linking Researchers to Their Journal Articles: An Overview of Unique Author Identifiers." Serials Review 43, nos. 3-4, 265-267. https://doi.org/10.1080/00987 913.2017.1386056.

Powell, James, Carol Hoover, Andrew Gordon, and Michelle Mittrach. 2019. "Bridging Identity Challenges: Why and How One Library Plugged ORCiD into Their Enterprise.” Library Hi Tech 27, no. 3, 625-39. doi.org/10.1108/LHT-04-2018-0046.

Riley, Lawrence E. and Elmer A. Spreitzer. 1970. "Book Reviewing in the Social Sciences." American Sociologist 5, no. 4 (November): 358-63. www.jstor.org/stable/27701668.

Runes, Dagobert. 1967. Treasury of Thoughts: Observations over Half a Century. Philosophical Library. Ann Arbor, MI: University of Michigan. Kindle.

Society of Biblical Literature. 2014. The SBL Handbook of Style. Second edition. Atlanta, GA: SBL Press.

—. 2019. “2019 SBL Membership Data.” www.sbl-site.org/assets/ pdfs/sblMemberProfile2019.pdf. Accessed January 2019.

Taylor \& Francis Group. 2017. "Co-authorship in the Humanities and Social Sciences: A Global View.” authorservices.taylorandfrancis. com/wp-content/uploads/2017/09/Coauthorship-white-paper.pdf. 
Tiliuțe, Doru E. 2016. "Digital Object Identifier for a Better Image of Scholar Journals." In The USV Annals of Economics and Public Administration, sixteenth special edition, 138-143. 


\section{ENDNOTES}

1 Incidentally, the citation search that the citation tracker embedded in the Proquest databases was found to be useful in finding citations that were present in unpublished theses but, otherwise, generally overlapped with Google Scholar in terms of journal citations for pbulications by faculty at UWG's COSS. Google Scholar was superior for unearthing citations of journal articles and unpublished papers that were in institutional repositories as well as edited books and monographs. Web of Knowledge (Web of Science) generally returned the fewest citations and tended to overlap those in either Google Scholar or ProQuest.

2 In my career as a librarian, I have always been able to include major reviews of over 1,000 words in my tenure and promotion portfolios, but I was encouraged that they should not represent more than $20 \%$ of my scholarly output in any five-year review period. This was an exception made, given the library side of my workload. My materials were reviewed by committees primarily comprised of biblical studies faculty, since I also taught biblical studies classes. Colleagues in biblical studies were advised by their own mentors to avoid presenting reviews as evidence of scholarly activity. Nonetheless, virtually all of my biblical studies colleagues at the various insituitons where I have worked produce book reviews as a by-product of both reading avariciously to remain current in their fields and providing feedback to colleagues who have taken the time to write book-length works.

3 Although I kept no formal count, it was obvious as I searched for faculty publications that very few of the books written by the COSS faculty had been reviewed by others. A chief exception was an introductory textbook written by a professor of psychology for which there were about three reviews.

4 The Taylor \& Francis survey was sent to 9,180 researchersin 63 countries who served as editors of Taylor \& Francis journals. Survey results were disaggregated by global region, age of respondent, and gender of respondent. I am uncertain about how many journals (if any) published by Taylor \& Francis are dedicated to biblical studies, though the publisher does produce the Journal of the European Pentecostal Theological Association, the journal titled Religion, and the Journal of Religious and Theological Information, which might 
include occasional articles focused on biblical studies. The remaining religion offerings are generally interdisciplinary, such as the Journal of Religion and Spirituality in Social Work and Religion, State \& Society.

5 While individual chapters in edited books were generally solo authored, the editorial activity of the volumes themselves was often collaborative. To break that down, within the 61 bilbographic entries, six were in books that had multiple editors, while only two were in volumes that had a single editor.

6 In fact, in addition to Sage, publishers of biblical studies and religious studies materials and journals like Elsevier, Cambridge University Press, Oxford University Press, ProQuest, and Taylor \& Francis are amongst the seventyseven publishers who are member organizations of ORCID. As time passes, one would expect other publishers of Bible content to join their ranks. These publishers were identified as ORCID members on June 15, 2020 by limiting the search of members in the ORCID registry (orcid.org/members) to only those identified as "publishers." Incidentally, I was not able to find Atla listed as a member organization when I sorted the full list of ORCID members by "associations" or publishers, but perhaps it was classified in some other way.

7 Instructions for doing so have been provided on a guide to ORCID produced by the Pao Yue-Kong Library at Hong Kong Polytechnic University (libguides.lb.polyu.edu.hk/orcid/ addworks).

8 The number of those holding ORICDs may be higher. It is possible to obtain an ORCID number without spending the additional time to complete a full profile on the site.

9 These statistics were compiled in early June 2020.

10 For instance, the URL for my own piece in the very first issue of $T L$ is theolib.atla.com/theolib/article/view/29, though the DOI is doi.org/10.31046/tl.v1i1.29. 